
\title{
PANDEMIA VIRAL E EXISTENCIAL: UM DESAFIO PARA OS
EDUCADORES E EDUCADORAS
}

Nize Maria Campos Pellanda ${ }^{1}$

\begin{abstract}
RESUMO
Esse artigo é datado no sentido de que trata do contexto atual da Pandemia do CONVID 19, sua gênese histórica e suas implicações físicas, existenciais, econômicas, políticas, sociais e epistêmicas. É um mundo que desaba no qual o papel dos educadores e educadorasé crucial. O eixo do texto, portanto, gira em torno da questão: - quaisos desafios que se colocam hoje aos educadores e educadoras diantede tamanha tragédia global? Para responder a esse questionamentoa $\mathrm{A}$ construí uma proposta de ressignificação da docência partindo da elaboração de um quadro teórico cujos pressupostos procedem do Paradigma da Complexidade que não separa as dimensões da realidade. Assim, a dimensão pessoal e singular são partes integrantesdo processo cognitivo que nada mais é do que o processo de viver. São trazidos exemplos de práticas didáticas autopoiéticas (construçãode si) para ilustrar uma docência ressignificada.
\end{abstract}

Palavras-chave: Autopoiesis; Docência. Ontoepistemogênese; Cognição;Biologia da Cognição.

\section{VIRAL AND EXISTENTIAL PANDEMIC: A CHALLENGE FOR EDUCATORS}

\section{ABSTRACT}

This article is dated in the sense that it addresses the current context of the CONVID 19 Pandemic, its historical genesis and its physical, existential, economic, political, social and epistemic implications. It is a collapsing world in which the role of educators is crucial. The axis of the text, therefore, revolves around the question: - what are the challenges facing educators today in the face of such a global tragedy? In order to answer this question, the A. builds a proposal to redefine teaching starting from the elaboration of a theoretical framework whose assumptions come from the ComplexityParadigm that does not separate the dimensions from reality. Thus, the personal and singular dimension are integral parts of the cognitive process that is nothing more thanthe process of living. Examples of autopoietic didactic practices (self-construction) arepresented to illustrate a resignified teaching.

Keywords: Autopoiesis; Teaching; Ontoepistemogenesis; Cognition. Biology of Cognition.

\footnotetext{
1 Graduada em História (UFRGS), mestrado em História da Cultura (PUCRS), doutorado em Educação(UFRGS) com doutoradosanduiche na M.U. (OHIO-USA). Professora do Programa de Pós-Graduação"Cognição, Tecnologias e Instituições" da UFERSA. Coordenadora da GAIA (Grupo de Ações e Intervenções Autopoiéticas).
}

Rev. Omni. Sapi., Mossoró, v.1, n.1, p. 87-97, ago./nov. 2021. 


\section{INTRODUÇÃO}

Desencantamento do mundo: em Descartes, ele se encarna no sujeito abstrato dopuro pensamento de si - aquele que não tem dor a mitigar, nem esperanças a realizar.Tanto o pensamento platônico como o cartesianismo, por razões diversas, implicaramnum universo desenfeitiçado, desmitizado, "sem qualidades", racional. No universo mítico e mágico, ao contrário, "nada é natural na natureza", tudo é sagrado (Olgária Matos). Vivemos momentos dramáticos da civilização! O mundo foi dilacerado! Nessa tragédia, perdeu-se o encantamento das relações integradoras ser humano-natureza, eu-outro, corpo-mente e assim por diante. Esse é um longo processo de fragmentação da realidade que iniciou na Grécia Clássica, tomou fôlego no início da Idade Moderna com a emergência do modo capitalista de produção, foi consolidado no neoliberalismo e chegou aos nossos dias com o impacto de suas consequências planetárias, políticas, sociais, econômicas, éticas, epistêmicas e existenciais. Esse é o tema desse texto: refletir sobre a crise que hoje pesa tanto sobre nós à luz de pressupostos epistêmicos e ontológicos procedentes de um novo paradigma, o da Complexidade, que não simplifica a abordagem da realidade, separando-a em diferentes seguimentos, mas, que pelo contrário, trabalha com convergências, isomorfismos, junções e complementariedades. Com essa plataforma epistêmica, explicito o que entendo por conhecimento e subjetividade de maneira inseparável uma da outra, amparando-me nas teorias complexas dos biólogos chilenos Humberto Maturana e Francisco Varela que revolucionaram a ciência a partir do berço cibernético. A grande inflexão que fizeram esses cientistas foi inverter a lógica formal da ciência hegemônica ao contemplar dimensões da realidade por ela negadas com a alegação de não serem objetivas e quantificáveis, tais como, o amor, o sagrado, a compaixão, o cuidado e outras. Nas suas teorias consagradas: a Biologia da Cognição de Maturana e Varela (1980), a Biologia do Amor de Maturana (1991) e a Enação de Varela (2000) trazem as questões do conhecer e do amar como condições biológicas de sobrevivência para os seres humanos, na medida em que conhecer e amar são inseparáveis no seu viver.

Como instrumento importante de auxílio a esse trabalho de compreensão de um contexto tão brutal, à luz da complexidade, lançamos mão também de uma Sabedoria Perene ${ }^{2}$ para incluir a voz daquelas pessoas que tiveram e têm maneiras sensíveis de olhar a realidade. Ainda bem que elas existem, pois, segundo a metáfora de Pierre Lévy, o grande arauto dos novos tempos e de um novo paradigma, numa leitura que faz da Bíblia, sugere que, se em Sodoma, conforme propõe Abraão, numa negociação com Deus, houver 50 justos, ela poderia escapar da destruição já imposta a ela pelos seus pecados? Abraão não conseguiu o número negociado e Sodoma foi aniquilada. Esperemos que haja hoje no mundo um número suficiente de justos e sábios para salvar a Sodoma contemporânea (LEVY, 1998).

Esse é um texto basicamente teórico, mas trazemos também alguns elementos empíricos que se referem ao processo didático que temos efetuado ao longo de décadas e que se concretizam através de práticas didáticas baseadas nos princípios de autoorganização, auto produção, autoconhecimento e numa lógica não-linear.

A partir dessas considerações iniciais formulo a questão que se desprende da temática apresentada acima: - quais os desafios que se colocam hoje aos educadores e educadoras diante de tamanha tragédia global?

\section{POR QUE COMPLEXIDADE?}




\begin{abstract}
“(...) a teoria do conhecimento e a teoria da vida nos parecem inseparáveis uma da outra" (Henri Bérgson).
\end{abstract}

Começo por explicitar o lugar de onde vou falar. Para abordar uma problemática de fundo para a educação me situo no Paradigma da Complexidade com a finalidade precípua de assumir uma atitude que junte os vários aspectos da realidade que entrou em degradação, justamente devido a uma fragmentação generalizada. Estamos falando de deterioração daquilo que chamamos de humano e isso passa por questões epistêmicas e ontológicas. Como urdidura teórica, portanto, lanço mão de um conjunto de pressupostos teóricos organicamente tecidos para enfrentar o tema proposto, ou seja, o processo de degeneração humana que se expressa na perda de autonomia/ autoria, de amorosidade e da dimensão do sagrado, o que implica em atravessamentos cognitivos de base. Considero o sagrado, no sentido batesoniano, como aquilo que liga os diferentes elementos da realidade (BATESON, 2000).

A ciência que herdamos da modernidade é uma ciência determinista e reducionista que tenta domesticar a realidade em equações lineares, controles e previsibilidade. É uma ciência da universalidade que não contempla o singular, o emergente e a autoorganização que está em toda a parte do cosmos. A epistemologia que subjaz a esta ordem é o racionalismo absoluto onde não há lugar para a intuição, a emoção e a criação tão importantes para uma lógica que se abre para a criação e o aleatório. No século XVII, devido à influência fundamental de Descartes como sistematizador da ciência moderna, o programa metafísico chega ao seu apogeu. Por incrível que pareça, surge na mesma época um filósofo que oferece um sistema filosófico oposto ao cartesiano por elaborar uma filosofia de holismo radical, a "substância única" acompanhado de uma teoria da afetividade humana que é um tratado de complexidade. Estou falando de Baruch de Espinosa. Trago aqui este sistema filosófico pelo fato de serem seus pressupostos estratégicos para tratar de nosso tema.

No século XIX, os cientistas começam a ser cada vez mais desafiados por situações complexas que não podiam ser abordados com os recursos lógicos tradicionais, trazendo, assim, a noção de energia ali onde somente se falava em universo inerte. A termodinâmica representou nesta ruptura um papel fundamental. A entropia foi a grande vilã desta virada, pois vai enfrentar o princípio de ordem universal de Newton. Subversivamente, a entropia foi mostrando a perda de energia e uma tendência à deterioração. Rupturas bruscas de materiais evidenciavam a força do caos até então negado. Outros fenômenos em outros campos do conhecimento desafiaram a eficiência das equações lineares e passaram a exigir uma outra abordagem matemática: as equações não-lineares. Por outro lado, por uma razão não-linear a entropia pode ser revertida em situações longe do equilíbrio, como a vida, por exemplo. Com isso, Prigogine ganhou o Prémio Nobel em 1977. Assim, nesta perspectiva de mudanças radicais vai surgindo um novo paradigma.

\footnotetext{
${ }^{2} \mathrm{~A}$ expressão sabedoria perene (sophia perennis) tem sido muito usada historicamente para designar um conhecimento básico e seminal sobre a realidade. Daí derivou-se mais recentemente uma Filosofia Perene (Philosophia Perennis) para expressar de maneira mais inteligível princípios que seriam fundantes da vida dos seres humanos e que estão presentes em muitas culturas e tempos diferentes. No fundo, o que subjaz a esses saberes, é uma filosofia que se sustenta no pressuposto de um princípio único, universal e perene. Em 1945, o escritor britânico Aldous Huxley consagrou a expressão com a publicação de seu famoso livro "Perennial Philosophy.
} 
O século XX começa com turbulência para falar a linguagem da termodinâmica: em 1900 Freud publica "A interpretação dos sonhos" com a noção de estar fazendo ciência da natureza. O contexto era de positivismo no qual o que importa para a ciência é o explícito e não o latente. $\mathrm{O}$ inconsciente, conceito central de Freud, é extremamente sutil e envolve uma lógica complexa sendo um fenômeno não-linear por excelência. Nas suas formulações, Freud é profundamente complexo porque se insere nas mudanças paradigmáticas de sua época, tendendo para ver o processo inconsciente como algo termodinâmico e não mecânico: um jogo de pulsões.

O movimento cibernético surgiu na década de 40 , propondo-se a enfrentar as questões da mente e da cognição de forma complexa, pois até então estes temas eram objetos apenas de especulações filosóficas. No seu início, na Primeira Cibernética, ainda encontramos muitos elementos de mecanicismo e racionalismo moderno, como as noções de entradas e saídas no sistema, bem como o pressuposto da existência de um mundo objetivo fora de nós, o que aproxima esta ciência de um caráter behaviorista. Mas o salto de atravessamento da fronteira paradigmática já havia sido dado, pois identificamos aí importantes avanços, como a própria abordagem sistêmica e o trabalho interno do sistema que se auto organiza e se auto alimenta (feedback). Além disso, a lógica circular presente neste sistema representada pela recursividade, já sinalizava uma abordagem mais complexa para fenômenos complexos.

A virada estratégica que representou um salto epistemológico radical foi a chegada de Heinz von Foerster às Macy's Conferences nas quais se constituiu a cibernética. Von Foerster inaugura uma segunda fase da Cibernética que inclui o observador no sistema observado e mostra que os sistemas aprendem ao operar. Como alerta Dupuy, não se trata mais de sistemas observados, mas de sistemas observantes (DUPUY, 1996). E pensando em educação, eu acrescentaria: nestes termos, não se pode mais falar em ensinar, mas em sistemas aprendentes, pois o que vem de fora não instrui, apenas chega como caos para ser auto organizado. Com esta atitude, inicia-se na ciência um outro patamar lógico que é a consideração de saberes reflexos (segunda ordem). Ora, isso força a epistemologia a se reconfigurar em termos de complexidade. A epistemologia que dai emerge começa a se constituir de forma cada vez mais viva e hoje é urgente trabalhar nesta tarefa de cartografar uma Epistemologia da Complexidade. Esta tarefa começa pela constatação do princípio da autorregulação presente em todos os sistemas vivos e segue pela inclusão dos saberes de segunda ordem, tais como: aprender a aprender, conhecer como se conhece e mudar na mudança que são elementos recursivos que implicam na volta ao sujeito que conhece e que se transforma ao mesmo tempo. Para Von Foerster (2003, p.248), ela precisa seguir na direção das operações do próprio observador. Tudo isso é explicitado na obra de von Foerster com o teorema: "Esta tarefa clama por uma epistemologia do - Como nós conhecemos, em vez de - O que conhecemos"? O trabalho ainda está em aberto e necessita responder às necessidades lógica de pesquisas cujos objetos se mostram cada vez mais desafiadores, como é o caso, por exemplo, das questões de autoconstrução. É por aí que o nosso grupo de pesquisa ${ }^{3}$ tem andado e a construção do conceito de Ontoepistemogênese é uma contribuição a esta demanda.

$\mathrm{Na}$ senda aberta por von Foerster seguiram biólogos que revolucionaram a Biologia, fazendo-a inseparável do processo de conhecer. Humberto Maturana e Francisco Varela cunharam sua teoria de "Biologia do Conhecer" para enfatizar esta inseparabilidade. Esta teoria é herdeira dos pressupostos epistêmicos e ontológicos da obra de von Foerster. 
Um exemplo deste parentesco é a pergunta de Maturana pelo conhecer: - em vez de perguntarmos - o que é isto? Perguntamos - como faço para conhecer isto?" (MATURANA; PORKSEN, 2004). Esta atitude representa uma mudança radical em epistemologia que se afasta cada mais do modelo aristotélico da preocupação com as coisas e suas categorias, com classificações e propriedades para se voltar para os processos.

O conceito-chave da Biologia da Cognição é Autopoiesis, palavra formada de dois vocábulos gregos: auto- por si e poiesis - criação. Com esta palavra, os autores queriam expressar a capacidade auto produtiva dos seres vivos e o fechamento dos sistemas vivos no seu operar. Para Maturana e Varela, os sistemas vivos são fechados para a informação e abertos para a troca de energia, princípio que eles herdam de von Foerster. Isso significa que o que vem de fora não determina o que acontece comeles, mas apenas mobiliza processos auto-organizativos que configuram a vida de cada ser vivo a partir de mecanismos internos. Assim, os seres humanos inventam asi mesmos ao viver.

Henri Atlan, foi outro importante biólogo que seguiu os passos de von Foerster, desenvolvendo a teoria da "Complexificação pelo Ruído", a partir do princípio foersteriano da "ordem pelo ruído". Atlan elabora uma teoria de aprendizagem usando como elemento organizador a ideia da auto-organização dos vivos que trabalham continuamente para criar ordem criativa do caos e, com isso, vão produzindo diferença de forma cada vez mais complexa, como é o caso do sistema cognitivo dos humanos. Diz ele: “... é como se o nosso aparelho cognitivo fosse uma espécie de aparelho criador, mais uma vez, de uma ordem cada vez mais diferenciada, ou seja, de complexidade a partir do ruído" (ATLAN, 1992, p. 123).

Este quadro básico de suporte para a construção do conceito oriundo da Cibernética vai sendo tecido com outros pressupostos complexos que vão sendo usados à medida em que vamos construindo a resposta para a questão colocada no início do texto. O importante neste momento é pensarmos em termos de complexidade, isto é, de inseparabilidades entre as diferentes dimensões da realidade. E isso nos leva necessariamente a algumas inferências abdutivas nas quais o ser humano singular é inseparável do todo. Isto quer dizer que, para pensarmos em cognição/subjetivação dos seres humanos temos que pensar em termos de relações vivas entre o todo e as partes nas quais as leis da natureza física estão presentes neste processo de constituição do vivo. Um exemplo muito claro disto é o de Prigogine, um dos primeiros cientistas a compreender a complexidade da natureza e a sua relação com a complexidade do ser vivo. Diz ele citando Bergson: "... o todo tem a mesma natureza que o eu e que o apreendemos mediante um aprofundamento cada vez mais completo de nós mesmos" (BERGSON, apud PRIGOGINE, 1992, p.23).

\section{UM CONTEXTO DESUMANIZADO E PROPOSTAS AUTOPOIÉTICAS DE AÇÃO}

\footnotetext{
${ }^{3}$ GAIA-Grupo de Ações e Investigações Autopoiéticas - CNPq - equipe cunha o termo ONTOEPISTEMOGÊNESE para se referir a um princípio organizadores dos seres humanos, segundo o qual cognição e subjetivação emergem juntas no processo de viver.
} 
Não será, então, que, mais do que relatar "uma experiência de vida vivida", a escrita é uma possibilidade de viver - e constituir-se - como experiência? Não será que, em vez de sermos sujeitos que "nos expressamos" na escrita, é a experiência mesma da escrita que nos constitui? Não estaremos nos tornando o que somos, ao escrever, mas do que escrevendo o que nos tornamos? (CRAGNOLINI, 2001, p.132).

Em 2016, quando um golpe parlamentar e jurídico tirou do poder uma presidente eleita sobre a qual não pesava nenhuma irregularidade, cresce de maneira dramática um processo de exclusão brutal que já vinha se impondo desde os anos $70 \mathrm{com}$ a emergência do neoliberalismo. O espetáculo do Congresso na votação de impeachment com os parlamentares se manifestando da maneira grotesca, mostrou até onde pode ir um ser humano na negação da realidade, do outro e de si mesmo. Seguiram-se os conhecidos desdobramentos deletérios do governo Temer que inicia um processo febril de desmonte do Estado e destruição dos direitos humanos.

A elite brasileira dispara um processo de manipulação ideológica que resultou na eleição de um homem que não tinha as mínimas condições políticas, morais, éticas, culturais e de saúde mental para governar. Milhões de pessoas deram seu aval a esse candidato. Esses eleitores voltam para suas casas tranquilamente depois de depositar seus votos nas urnas como se seus votos não tivessem consequências. Isso me faz lembrar a narrativa de Hanna Arendt sobre o julgamento de Eichmann em Jerusalém (ARENDT, 2017), mostrando um réu impassível, sem o menor sinal de culpa. Nos dois casos, trata-se da "banalização do mal" como enfatizava a filósofa.

E aí entramos na questão da patologia. Vivemos uma civilização de fragmentações que separa as diferentes dimensões da realidade. Os seres humanos não se sentem parte da natureza e não se reconhecem no outro. Essa fragmentação configura uma cultura patológica pela negação da natureza na sua condição viva e a dos seres humanos como seres amorosos. São as consequências existenciais de um paradigma fragmentador que dilacerou a vida dos seres humanos e natureza em geral. Aliás, diga-se de passagem, essas duas realidades não podem ser separadas porque nós somos a natureza.

Hoje a natureza está cobrando a conta. Não fosse esse o vírus, seria um outro: a pandemia do Coronavirus, foi prevista já há alguns anos, não chega por acaso. Ela foi gestada no bojo de uma cultura dividida e doente. A pandemia existencial no Brasil atingiu milhões de pessoas que contribuíram para criar as condições de desequilíbrios do planeta. A pandemia do Coronavírus emergiu nesse caldo. Esse tipo de pandemia é algo doloroso, pois inúmeros seres humanos perderam algo vital: a amorosidade e a autoria de si mesmos. Mas os turbilhões da vida podem nos ensinar a reverter o caos e fazer emergir o cosmos resgatando, assim, nossa condição amorosa e parte integrante da própria natureza.

Diante de tal cenário tão desumanizante e preocupante que carrega o perigo de uma manipulação tão sutil perpetrada por uma classe dominante muito mais forte e anônima do que nos tempos do liberalismo e do neoliberalismo, é preciso uma postura muito consciente de nós mesmos para não soçobrar no obscurantismo, como também, para ajudar aos outros a não sucumbir.

Para entendermos a manipulação sofisticada da dialética opressor-oprimido presente nesse contexto, é preciso identificar os fenômenos que minam os processos educativos. Por traz de tudo isso, a ideologia neoliberal agora revestida de maior poder de dominação pela convergência de forças do CMI (Capitalismo Mundial Integrado). Há todo um aparato ideológico perverso e invasivo cujo imperativo primeiro é a subjetividade controlada e 
limitada de tal forma que se transforma em autovigilância, pois o próprio oprimido se encarrega de sua opressão. Este é o caso dramático do que acontece atualmente no Brasil onde se viram, lado a lado com a elite, pessoas das classes populares pedir nas ruas a saída da presidente eleita, íntegra e responsável por avanços sociais significativos e clamando por um grupo de políticos corruptos, comprometido com o capital internacional com um programa de privatizações e cancelamento das políticas públicas. É a produção de ignorância em grau altamente requintado. Esse é o contexto que me interessa focar para poder refletir sobre como funciona cognitiva e ontologicamente uma lógica linear e binária.

Tudo parece sucumbir à lógica do grande capital. As necessidades humanas básicas não interessam a esse sistema que se concentra cada vez mais nas mãos de poucos enquanto aumenta a miséria no mundo. Valores fundantes do humano são negados. O que nos resta fazer diante de um poder tão intenso são as micropolíticas de resistência via educação, arte etc. Nesse sentido, a questão do conhecimento, da autoria e da ressignificação da docência são fundamentais. Conhecer, na perspectiva de condição biológica e de uma sabedoria perene, significa aprender a viver, a ser autor de sua própria vida. A docência, nessa mesma linguagem, seria, então, o desenvolvimento de habilidades do docente de devir junto com seus alunos, não ensinando porque isso é impossível, mas acompanhando-os e ajudando-os a encontrar seus graus de potência. Para Maturana e Varela (1980), o cérebro é uma rede fechada que não se comunica com o exterior. O que vem de fora não determina o que acontece com o ser vivo, mas apenas perturba, disparando ações neurofisiológicas que reconfiguram todo o organismo (1980). Para Espinosa (1983), não somos seres de essência, mas graus de potência a serem desenvolvidos a partir de afecções. O docente seria aquele que afecta e promove afecções, que acolhe os seus/suas alunos (as) em sua autoria para que ele possa construir sua autopoiesis.

Como parte, portanto, de um grande plano de dominação, como já referido, está presente um projeto de educação formal, de uma lógica reducionista para justamente esvaziar o processo de conhecer de seu potencial de autonomia, autoria e liberação para formar pessoas dóceis e incapazes de pensamento abdutivo, ou seja, aquele que junta as diferentes dimensões da realidade. Esse projeto político-pedagógico está sendo sustentado pelos donos do capital atual, com poder político e econômico cada vez mais concentrado em suas mãos. Muitos são os educadores que aderem a esse plano diabólico por terem perdido a autoria de si mesmos sucumbindo à avalanche neoliberal. Não podemos sucumbir a essa lógica desumana como está acontecendo com diferentes segmentos no Brasil e no mundo. Nesse sentido, não podemos abrir mão de nossas armas e de nossa arena de luta. Um currículo voltado para a vida éo nosso palco de luta. $O$ educador hoje precisa ter uma formação tal que passe pelo entendimento de uma epistemologia viva. Não falo de uma epistemologia engessada por categorias rígidas e abstratas voltada para a ideia de um conhecimento representacional, herdada de uma tradição metafísica de 2500 anos, responsável por uma cultura que matou o sujeito. Falo de uma epistemologia da vida concreta de cada momento, aquela que é capaz de inventar uma arte de viver. Não falo de uma ontologia essencial do ser pronto, mas fazendo-se a cada momento do viver. Assim, epistemologia e ontologia são inseparáveis. Por isso, no GAIA (Grupo de Ações e Intervenções Autopoiéticas), nosso grupo de pesquisa, cunhamos o conceito de Ontoepistemogênse, como um princípio operador que nos mostra que conhecer é transformar-se.

A proposta aqui é inventar novas formas revolucionárias perpassadas por 
amorosidade, afirmadoras de diferença e de autoria, tais como micropolíticas, práticas do cuidar que desestabilize os fortes esquemas de poder, mobilizações ecológicas etc. No que diz respeito à educação formal, poderíamos adotar, por exemplo, a prática das auto narrativas e processos que respondem a uma demanda biológica e existencial dos seres humanos, a autoprodução ou autopoiesis já referida acima. Nesse sentido, as estratégias ideológicas de manipulação do ego via inconsciente são devastadoras do humano. As políticas de exclusão brutal produtoras de pobreza e ignorância apostam no sofrimento, na fome e na tristeza. Para Espinosa, a tristeza despotencializa e a alegria os empodera (op. cit.). Façamos, pois, da alegria, da amorosidade e da autopoiesis as nossas armas revolucionárias.

Trago, aqui, minha própria experiência docente, calcada numa pedagogia autopoiética, ou seja, uma praxis pedagógica na qual o discente dá conta de suas próprias operações epistêmicas e ontogênicas, sempre na perspectiva ontoepistemogênica, evidenciando, portanto, uma transformação pessoal que emerge junto com o processo cognitivo. Para Espinosa, conhecer é afectar-se e o conhecimento seria o mais potente dos afetos (ESPINOSA, 1983). Uma dessas formas é a auto - narrativa que acompanha todo o trabalho didático das disciplinas nas quais trabalho... Essas auto - narrativas algumas vezes são feitas em uma roda de conversa para os colegas e, em outras, na intimidade do encontro consigo mesmo. No primeiro caso, tem o objetivo de afectação mútua, sensibilizando sobre as histórias do outro, disparando a empatia e, no outro caso, o autoencontro oportuniza a auto afecção no sentido de levar a processos de segunda ordem, ensejando, assim, auto apropriações, tais como, pensar seu próprio pensar, conhecer como se conhece e assim por diante. Essa é uma maneira de preservar nossa autoria/autonomia e não sucumbir às manipulações ideológicas que nos invadem de modo perverso nos tirando a energia criadora que emerge da autenticidade do nosso eu real. A seguir, fragmentos de auto - narrativas de alunos e de alunas de disciplinas de curso de pós-graduação strictu sensu nas quais atuei como docente:

\section{Em uma roda de conversa:}

\section{Fragmento 1:}

"A dinâmica foi a teia de narrativas, na qual todos estiveram em círculo e, à medida que iam contando sobre si aos colegas, jogavam um fio ao outro, fio este que nos uniu ao final de todos os discursos, formando uma teia que nos interligava. Quando chegou a minha vez de falar, senti que não conseguiria fazê-lo sem emoção, porque,para mim, retornar em pensamento e falar tudo o que já vivi, me toca de uma maneirainigualável". J.

Para si mesmo:

\section{Fragmento 2:}

"Tudo isso me remete à noção de intuição como uma forma de conhecimento inteiro, sem representação, sem fragmentação, ausente de intervenções. Reflito sobre isso e imediatamente lembro da poesia, para mim a melhor representação da intuição, do pensar complexo. Ligado às emoções e às incertezas, o fazer poético é apura energia da matéria. Já que conhecer é viver, posso afirmar que vivi muito todos os 
encontros da disciplina: na meditação, no ato de colorir a mandala ou de produzir o haicai, na reflexão do filme Quem somos nós ou do documentário O que é a Teoriada Complexidade e em todos os lindos momentos vividos ao longo desses quase três meses. Sinto que tenho em mim um mundo de possibilidades!" R1.

\section{Fragmento 3:}

"A complexidade da vida representada por nossas histórias. Afinal, nós somos o relato de nós mesmos. Relatar nossas vidas é exercício de dar sentido às mesmas e relatar nossa experiência será sempre ligado às nossas emoções”. A.

\section{Fragmento 4:}

"Acontece, minha gente, que eu quero ser eu, mas um outro eu. A questão do eu e do outro me inseriu numa cilada semântica. Se eu desejo ser outro, isso pressupõe um não-eu? Procuro as palavras mais apropriadas para reverter a situação, mas todas parecem conspirar meu primo. Assumo o nocaute já no primeiro round do embate retórico". V.

\section{Fragmento 5:}

"Se na disciplina cursada no ano passado como aluna especial pude me surpreender com muitas quebras de paradigmas contemporâneos, especialmente no que tange às tecnologias e às bases do ser humano como sua formação emocional e construção enquanto caráter, amorosidade, por exemplo, apropriando-se das tecnologias de ponta, nessa disciplina assim como em outras cursadas esse ano, me percebo refletindo sobre a complexidade de um jeito realmente distinto e envolvendo diversas conexões de um jeito "complexo" na vida de cada ser humano e não para a possível simplificação desse termo complexidade, como pode parecer num primeiro momento, de resumir toda ideia de complexidade em um ser humano apenas como alguém cheio de coisas, por exemplo. Sou capaz de compreender melhor o conceito inerente à palavra complexidade e tenho maior convicção de que a percepção é algo inerente a qualquer método de pesquisa e que essa percepção utiliza-se dos sentidos humanos para tornar-se viva, e aí encontra o ponto comum com a minha busca pessoal enquanto pesquisadora: a relação complexa que acontece entre os 5 e talvez mais sentidos físicos que possuímos". R.W.

Esses exemplos servem para mostrar a força epistêmica e ontológica de falar em primeira pessoa, pois conhecer começa pelo autoconhecimento porque na perspectiva biológica da autopoiesis não podemos conhecer nada fora de nós mesmos porque somos o próprio processo observado. A abordagem patogênica, realidade que separa sujeito e objeto nos privou do mais fundamental: a autoria de nossa própria vida. Com isso, ficamos à mercê da manipulação e da opinião dos outros (VARELA, 2000).

\section{CONSIDERAÇÕES FINAIS}

"O príncipe-pássaro rompeu seus laços: dirige seu voo em direção ao sul e à Gaia Ciência, a ciência da salvação do gozo, da poesia, do amor (que ironia)" (F. Nietzsche). 
O que tentei fazer aqui foi, na verdade, um relato de mim mesma, da minha perplexidade frente a uma realidade tão trágica como a que estamos vivendo.

Como educadora, fui profundamente afectada por esse círculo de horrores que se tornou meu país. Milhões de brasileiros foram às urnas dar seu voto a um governo cujo modelo é o apelo à exclusão brutal. Oprimidos idolatrando o opressor. Os direitos humanos anulados gradativamente. Parlamentares e juristas optam pela omissão. A destruição ambiental é incentivada. O país perde a cada dia a sua autonomia. Nada disso serve para acordar as pessoas porque estão adormecidas sob o efeito dos narcóticos desumanos da colonização das consciências, pois perderam a capacidade de gerir a si mesmas.

$\mathrm{E}$, diante de tudo isso, nós, educadores e educadoras, comprometidos com a tarefa de educar o que podemos fazer diante do caos? De minha parte, aposto nas lições de sabedoria de viver o que aprendi com os pressupostos do Paradigma da Complexidade que nada mais são do que a sabedoria de homens e mulheres despertos de todos os tempos. Assim, as noções de uma natureza viva que produz e dispersa energia, de princípios de auto-organização, da amorosidade como filogeneticamente fundante do humano, da autoria de nossa própria vida como algo sagrado no sentido já referido, levam-me a pensar que ainda é possível transformar o caos em cosmo, a entropia do ódio na neguentropia do amor através de práticas que resgatem o sentido do "humano, demasiadamente humano" (NIETSZCHE, 1983). E que possamos então, como sugeria Espinosa, tantas vezes referido nesse texto, assumir a nossa identidade de seres divinos, pois, numa perspectiva de complexidade radical não existem duas substâncias no Universo, Nós e Deus constituímos uma mesma entidade (ESPINOSA, 1983).

O que precisamos é repensar nossa docência à luz daquilo que realmente importa no sentido humano. O que descrevi aqui foram reflexões baseadas no Paradigma da complexidade para servir de suporte para a compreensão do que constitui a humanidade, partindo de uma abordagem biológica. Fora da amorosidade, do cuidado, da compaixão, da noção da natureza como algo sagrado que nos constitui, não há como sobreviver. Esqueçamos, pois, os famigerados "conteúdos" para dar lugar ao autoencontro, à experiência do viver no fluxo vital nos quais não há conteúdos mas apenas vivências porque não podemos conhecer nada a não ser aquilo que faz parte de nós mesmos.

Pensando nas considerações aqui apresentadas, a invenção da docência em termos autopoiéticos, é fundamental, não somente para uma vida plena de sentido humano, como também para a própria sobrevivência da vida no planeta. Termino com as palavras de Maturana: "A emoção fundamental que faz possível a história da hominização (MATURANA, 1991, p.211).

\section{REFERÊNCIAS}

ARENDT, H. Eichman em Jerusalém: um relato sobre a banalidade do mal. Lisboa: Itaca, 2017.

ATLAN. H. Entre o cristal e a fumaça: ensaio sobre a organização do ser vivo. Rio de Janeiro: Jorge Zahar, 1992.

BATESON, G.; BATESON, M.C. El temor de los angeles. Barcelona: GEDISA, 2000. ESPINOSA, B. Ética. São Paulo: Abril, 1983.

LEVY, P. Inteligência Coletiva. São Paulo: Loyola, 1998. 
MATURANA, H. Emociones y lenguaje en Educacion y Política. Santiago: Hachette, 1991.

MATURANA, H. R.; PÖRKSEN, B. Del ser al hacer. Santiago, Chile: Jcsáez Editor, 2004.

MATURANA, H.; VARELA, F. Autopoiesis and cognition. Dortercht: Reidl, 1980.

NIETZSCHE, F. Nietzsche. São Paulo: abril, 1983.

PRIGOGINE, I.; STENGERS, I. Entre o tempo e a eternidade. São Paulo: Cia das Letras, 1992.

VARELA, F. El Fenomeno de la vida. Santiago: Dolmen, 2000.

VON FOERSTER, H. Understanding understanding. New York: Spring, 2003 